\title{
MOVING EQUILIBRIA IN THE PUBLIC HEALTH CARE SECTOR: A LOW-QUALITY TRAP AND A RESOLUTION
}

\author{
AHMET KARA \\ Received 22 March 2006; Accepted 16 May 2006
}

This paper demonstrates the existence, in a particular subset of the Turkish public health care sector, of equilibria moving towards a low-quality trap over time. The dynamics of the movement in question hinges, in part, on the socially necessary but demographically asymmetric burden, on some public health care institutions, of providing affordable health care to certain sections of the population. The paper formulates a policy option that could help the sector to escape the trap, moving the sector towards high quality-high welfare equilibria.

Copyright (C) 2006 Ahmet Kara. This is an open access article distributed under the Creative Commons Attribution License, which permits unrestricted use, distribution, and reproduction in any medium, provided the original work is properly cited.

\section{Introduction}

The literature on the health care sector includes a rich array of works including [1,3-11]. (We selectively draw upon the literature that contains a large number of works. We cite only the most relevant ones.)

These works explore a number of issues ranging from total quality in health care to issues of patient satisfaction. As rich as the coverage of these works is, a variety of issues remain under-explored, and there are a number of problems and complexities arising from the dynamics of the service sectors that are worthy of further explorations. In this paper, we will follow the line of inquiry initiated by Kara [4] so as to examine the low quality-low satisfaction trap arising from the moving equilibria in a particular subset of the health care sector in Turkey. We will propose a policy option that could get the sector out of the trap in question.

In Section 2 of the paper, we develop the model. Section 3 presents the empirical results. The policy implications are articulated in Section 4 . The concluding remarks follow in Section 5. 


\section{The model}

(The model benefits from the work by Kara [4]. However, the central concept and model that our analysis is based on, namely "moving equilibrium in the public health care sector," is developed in this paper.) Consider a service sector where suppliers provide a service, say $x$, to the customers. Let $P_{t}$ be the service performance at time $t$, the measurement of which is based on a questionnaire given in Appendix B. Let $R_{t}^{p}$ be the repurchase intention in the sector, which indicates the degree to which customers are willing to repurchase the service at time $t . R_{t}^{p}$ depends on service quality, $Q_{t}$ and $Q_{t-1}$, at time $t$ and $t-1$, and service performance, $P_{t}$ and $P_{t-1}$, at time $t$ and $t-1$, that is,

$$
R_{t}^{p}=f\left(Q_{t}, Q_{t-1}, P_{t}, P_{t-1}\right)
$$

Let $R_{t}^{s}$ be the suppliers' resale intention in the sector, which indicates the degree to which suppliers are willing to "resupply" the service at time $t$. Suppose that $R_{t}^{s}$ depends on service quality, $Q_{t}$ and $Q_{t-1}$, at time $t$ and $t-1$, and service performance, $P_{t}$ and $P_{t-1}$, at time $t$ and $t-1$, that is,

$$
R_{t}^{s}=g\left(Q_{t}, Q_{t-1}, P_{t}, P_{t-1}\right)
$$

(Repurchase intention and resale intention equations could be obtained through utility maximization and profit maximization, respectively. For a demonstration, see [4] where the rationale for the other equations that this model is based on is explained as well.) (The measurement of the variables $R_{t}^{p}, R_{t}^{s}, E_{t}, S_{t}$ are based on a questionnaire given in Appendix B.)

For analytical purposes, we will assume that the dependence of the repurchase and resale intention on the present and past qualities and performances has the following forms:

$$
\begin{aligned}
& \ln R_{t}^{p}=\alpha_{0}+\alpha_{1} \ln Q_{t}+\alpha_{2} \ln Q_{t-1}+\alpha_{3} \ln P_{t}+\alpha_{4} \ln P_{t-1}, \\
& \ln R_{t}^{s}=\beta_{0}+\beta_{1} \ln Q_{t}+\beta_{2} \ln Q_{t-1}+\beta_{3} \ln P_{t}+\beta_{4} \ln P_{t-1} .
\end{aligned}
$$

Here a peculiar feature of the supply behavior of the public health care institutions needs to be noted: even at low performance and quality levels, many public institutions do end up supplying services, partly because of the necessity to provide services to low-income people even in cases where resources are not sufficient. With insufficient resources, services could be provided at low quality and low performance. The level of these minimally necessary services at time $t$ depends on the level of these services at $t=0$, and the growth rate of these services. Let at, the minimal performance and quality levels, $R s$ have the value of $A$, which grows at a rate of $g$ over time. Thus, at $Q_{t}=1, Q_{t-1}=1, P_{t}=1$ and $P_{t-1}=1, R_{t}^{s}=A(1+g)^{t}, \ln R_{t}^{s}=t \cdot \ln A(1+g)=\beta_{0}$. 
To theorize about the movements over time (i.e., the dynamic trajectory) of service performance, we will make the following reasonable assumption, which is compatible with the logic of the market process: it is the relative strength (or magnitude) of the repurchase intention compared to the resale intention that provides the impetus for the quality to be adjusted upwards over time.

Formally,

$$
\frac{Q_{t+1}}{Q_{t}}=\left(\frac{R_{t}^{p}}{R_{t}^{s}}\right)^{k}, \quad \text { where } k \text { is the coefficient of adjustment. }
$$

Taking the logarithmic transformation of both sides, we get

$$
\ln Q_{t+1}=\ln Q_{t}+k\left(\ln R_{t}^{p}-\ln R_{t}^{s}\right)
$$

We will call this the dynamic adjustment equation. Substituting the functional expressions (forms) for $\ln R_{t}^{p}$ and $\ln R_{t}^{s}$ specified above, setting the value of present and past performances to their average values, $P^{\mathrm{avr}}, P^{\mathrm{avr}-1}$, and rearranging the terms in the equation, we get

$$
\begin{aligned}
& \ln Q_{t+1}+\left(k \beta_{1}-k \alpha_{1}-1\right) \ln Q_{t}+\left(k \beta_{2}-k \alpha_{2}\right) \ln Q_{t-1} \\
& \quad=k\left[\alpha_{0}+\left(\alpha_{3}-\beta_{3}\right) \ln P^{\mathrm{avr}}+\left(\alpha_{4}-\beta_{4}\right) \ln P^{\mathrm{avr}-1}\right]-[k \ln A(1+g)] t,
\end{aligned}
$$

which is a second-order difference equation, the solution of which is provided in Appen$\operatorname{dix} \mathrm{A}$.

The solution in Appendix A shows that the intertemporal equilibrium quality, $Q^{*}$, is

$$
Q^{*}=e^{\left[k\left[\alpha_{0}+\left(\alpha_{3}-\beta_{3}\right) \ln P \operatorname{avr}+\left(\alpha_{4}-\beta_{4}\right) \ln P \text { avr }-1\right]+[\ln A(1+g)]\left[1-k\left(\beta_{2}-\alpha_{2}\right)\right] /\left[\left(\beta_{1}+\beta_{2}\right)-\left(\alpha_{1}+\alpha_{2}\right)\right]\right] /}
$$

which is time-dependent, indicating a moving equilibrium. To study whether this intertemporal equilibrium quality is high or low, and whether it remains stable over time, we need to empirically estimate the parameters involved. This is done in the next section.

\section{Empirical analysis}

3.1. The sample. Data for this study was gathered using a questionnaire, originally developed by Carman (1990). A few questions designed by Cronin and Taylor (1992) were added to the questionnaire. The questionnaire was distributed to the patients in the nonprofit $X$ hospital in two consecutive time periods. In the first period 200 patients were asked to respond to the questions. One hundred and fifty useable questionnaires were returned giving a response rate of 75 percent, which was considered satisfactory for subsequent analysis. The original version of the questionnaire was developed in English. This questionnaire was translated into the local language (Turkish). The local version was 
retranslated until a panel of experts agreed that the two versions were comparable. Each item was rated on a seven-point Likert scale anchored at the numeral 1 with the verbal statement "strongly disagree" and at the numeral 7 with the verbal statement "strongly agree." (Alternatively, we can map each integer scale in question to an interval, that is, 1 could be mapped to $[0,1]$.) This format has been recommended for the health care survey. The questionnaire was pretested several times to ensure that the wording, format, and sequencing of questions were appropriate. The questionnaire is given in Appendix B. The same procedure has been repeated to obtain the data for the second period.

3.2. Estimation of the parameters. To estimate the parameters involved, we formulate the following regression equations:

$$
\begin{aligned}
& \ln R_{t}^{p}=\alpha_{0}+\alpha_{1} \ln Q_{t}+\alpha_{2} \ln Q_{t-1}+\alpha_{3} \ln P_{t}+\alpha_{4} \ln P_{t-1}+u_{t}, \\
& \ln R_{t}^{s}=\beta_{0}+\beta_{1} \ln Q_{t}+\beta_{2} \ln Q_{t-1}+\beta_{3} \ln P_{t}+\beta_{4} \ln P_{t-1}+v_{t},
\end{aligned}
$$

where $u_{t}$ and $v_{t}$ are disturbance terms.

3.2.1. Repurchase intention equation. Since in the context of the particular health sector under examination buyer behavior appears to be linked largely to the present quality and past performance, we assume, for the sake of simplicity, that $\alpha_{2}=0$ and $\alpha_{3}=0$. (Patients are asked to evaluate the service performance while or after they are discharged. So their evaluations are about the past performance. On the other hand, however, their overall quality assessments are influenced by the presence or absence of certain quality procedures in the present period. In view of these peculiarities, repurchase intention could be taken as a function of present quality and past performance.) Since minimum quality and performances induce minimum repurchase behavior, then $\alpha_{0}=0$. Thus, we formulate the following special version of the repurchase-regression equation stated above:

$$
\ln R_{t}^{p}=\alpha_{1} \ln Q t+\alpha_{4} P_{t-1}+z_{t},
$$

where $\mathrm{z}_{t}$ is the disturbance term. The regression-results are as follows:

$$
\ln R_{t}^{p}=0.902 \ln Q t+0.149 \ln P_{t-1}
$$

$$
(10.154)(1.696)
$$

$R^{2}=0.98, t$-statistics are given in parentheses. Thus,

$$
\begin{gathered}
\alpha_{0}=0, \quad \alpha_{1}=0.902, \\
\alpha_{2}=0, \quad \alpha_{3}=0, \quad \alpha_{4}=0.149 .
\end{gathered}
$$

3.2.2. Resale intention equation. To estimate the parameters of the resale intention equation, we asked an official of the hospital questions, the answers of which were designed to give the values of the elasticities of resale intention with respect to the present and 
past quality and performances. The answers indicate that a $1 \%$ increase in the past quality would increase the resale intention by about $0.25 \%$, but a $1 \%$ increase in the present quality would increase the resale intention by about $0.75 \%$. Thus,

$$
\beta_{1}=0.75, \quad \beta_{2}=0.25
$$

Similarly, a $1 \%$ increase in the past performance would increase the resale intention by about $0.10 \%-0.15 \%$. The approximate value is $0.125 \%$. Thus,

$$
\beta_{4}=0.125 \quad \text { (approximately). }
$$

The value of $A$ is normalized to 1 , which is assumed to grow at an approximate rate of $0.1 \%$.

3.2.3. The coefficient of adjustment $(k)$. For simplicity, we will assume that $Q_{t+1} / Q_{t}$ is proportional to the ratio of repurchase intention to resale intention, and hence, $k=1$.

Given the values of the parameters above, we can now determine the value of intertemporal equilibrium quality, which is

$$
Q^{*}=e^{1.186-0.101 t}
$$

indicating a diminishing quality over time (a moving equilibrium). At $t=0, Q^{*}=3.27$, at $t=1, Q^{*}=2,96$, and so forth. With basic parameters remaining the same, the sector slides into a low-quality trap over time. As proven in Appendix A, this low quality is also stable over time.

This trap is in a part a byproduct of the particular trajectory of migration in Turkey, which results in a positive growth rate in minimally necessary services in some places (places like Istanbul) and a negative growth rate in other places. In places characterized by a positive growth rate, if capacity and resource constraints (affecting supply) remain the same, increasing services are provided at a low quality.

This low service quality has a considerable effect on the service satisfaction. To analyze the quality-satisfaction relationship in a formal manner, suppose that service satisfaction depends on the quality and performance in the following way:

$$
\ln S_{t}=\delta_{0}+\delta_{1} \ln Q_{t}+\delta_{2} \ln P_{t-1}+u_{t}
$$

where $S_{t}$ denotes the service satisfaction at time $t$ and $u_{t}$ is the disturbance term. The regression results based on the data available are as follows:

$$
\begin{aligned}
\ln S_{t}= & -0.402+1.070 \ln Q_{t}+0.164 \ln P_{t-1} \\
& (-2.296) \quad(13.461)
\end{aligned}
$$

$R^{2}=0.657, t$-statistics are given in parentheses.

Given the value of the intertemporal equilibrium quality and the average value of past performance, we can now calculate the value of the intertemporal equilibrium satisfaction 
$S^{*}$, for instance, at $t=0$.

$$
\ln S^{*}=-0.402+1.070 \ln Q^{*}+0.164 \ln P^{\mathrm{avr}} .
$$

Substituting the values of $Q^{*}$ and $P^{\text {avr }}$ at $t=1$, and solving for $S^{*}$, we get

$$
S^{*}=3.12
$$

which is low in view of the satisfaction scale of 1 to 7 . Thus, the low intertemporal equilibrium quality induced a low intertemporal equilibrium service satisfaction in the Turkish public health-care sector, indicating a low quality-low satisfaction trap facing the Turkish nonprofit health-care sector across time. Considering that public health-care institutions perform a useful social function of providing affordable health-care services to people who would not otherwise have access to such services, an inquiry into possible measures or policies that could help avoid such equilibria would be a worthwhile project to undertake. The following section will formulate one possible policy that enables the sector in question to get out of such trapping equilibria.

\section{Policy implications}

Since performance is one of the determinants of the repurchase intention, which influences quality through the dynamic adjustment process captured by the dynamic adjustment equation, elasticities of repurchase intention with respect to (past and present) performances are among the key parameters to play with for policy formulation purposes. A careful examination of the expressions for intertemporal equilibrium quality reveals that increases in the elasticities in question $\left(\alpha_{3}\right.$ and $\left.\alpha_{4}\right)$ will increase the intertemporal equilibrium quality (i.e., the comparative static derivatives of $\mathbf{Q}^{*}$ with respect to $\alpha_{3}$ and $\alpha_{4}$ are positive). Similar to the price elasticities of demand in the standard economic theory, performance elasticities of repurchase intention are likely to be higher in cases where customers face more options. As a policy option, the government could help increase the health care options by encouraging competition in the health care market. As an exercise, suppose that the value of $\alpha_{4}$ has increased by $20 \%$. Recalculating the intertemporal equilibrium quality, we get

$$
Q^{*}=e^{1.693-0.101 t}
$$

At $t=0, Q^{*}=5.43$. The associated intertemporal equilibrium satisfaction is $S^{*}=5.37$.

Thus, the intertemporal equilibrium quality for $t=0$ has increased from 3.27 to 5.43 and the intertemporal equilibrium satisfaction has increased from 3.12 to 5.37 . In view of the quality and satisfaction scale of 1 to 7 , the new values of intertemporal equilibrium quality and satisfaction are considerably high. (The same exercise could be repeated for $t=1,2,3, \ldots$.) Hence increasing the performance elasticities of repurchase intention will help the sector move from a low quality-low satisfaction (welfare) equilibrium to a high quality-high satisfaction (welfare) equilibrium. 


\section{Concluding remarks}

The model developed in the paper demonstrates the existence of equilibria in the Turkish public health care sector moving towards a low-quality trap over time, and as such, it identifies and explains an important problem characterizing the sector in question, and provides a simple analytically-tractable solution indicating a possible way out of the trap. The framework also serves as a basis for a simple measurement of satisfaction and hence welfare gains. The paper has, however, a number of limitations: the model is a partial equilibrium one focusing on a state-dominated subset of the health care sector, and as such, it does not take into account the interactions among the different subsets of the health care sector. Nor does it take into consideration the multidimensional linkages and complex interrelations among the health care-related sectors of the economy. Such linkages and interrelations, which are a key to a comprehensive measurement of the policy-induced welfare gains in particular and an in-depth grasp and a comprehensive understanding of the health care sector in general, could be best studied in a general equilibrium framework, which is worthy of future research.

\section{Appendices}

\section{A. The second-order difference equation: the solution}

(For a variety of exercises similar to this one, see $[2,4]$.)

The solution for the second-order difference equation,

$$
\begin{aligned}
& \ln Q_{t+1}+\left(k \beta_{1}-k \alpha_{1}-1\right) \ln Q_{t}+\left(k \beta_{2}-k \alpha_{2}\right) \ln Q_{t-1} \\
& \quad=k\left[\alpha_{0}+\left(\alpha_{3}-\beta_{3}\right) \ln P^{\mathrm{avr}}+\left(\alpha_{4}-\beta_{4}\right) \ln P^{\mathrm{avr}-1}\right]-[k \ln A(1+g)] t
\end{aligned}
$$

has two components, namely a particular solution and a complementary function. We will find these components for $\ln Q_{t}$ and then take the antilog of $\ln Q_{t}$ so as to find the solution for $Q_{t}$.

A.1. Particular solution. Let us try the solution $\ln Q_{t}=a_{0}+a_{1} t$. Substituting this into the second order equation above, and matching the coefficients, we get

$$
\begin{aligned}
a_{0}= & {\left[k\left[\alpha_{0}+\left(\alpha_{3}-\beta_{3}\right) \ln P^{\mathrm{avr}}+\left(\alpha_{4}-\beta_{4}\right) \ln P^{\mathrm{avr}-1}\right]\right.} \\
& \left.+[\ln A(1+g)]\left[1-k\left(\beta_{2}-\alpha_{2}\right)\right] /\left[\left(\beta_{1}+\beta_{2}\right)-\left(\alpha_{1}+\alpha_{2}\right)\right]\right] \\
& \times \frac{1}{k\left[\left(\beta_{1}+\beta_{2}\right)-\left(\alpha_{1}+\alpha_{2}\right)\right]} \\
a_{1}= & -\left[\frac{[\ln A(1+g)]}{\left[\left(\beta_{1}+\beta_{2}\right)-\left(\alpha_{1}+\alpha_{2}\right)\right]}\right] .
\end{aligned}
$$


8 Moving equilibria in the public health care sector

Thus,

$$
\begin{aligned}
\ln Q^{*}=[ & k\left[\alpha_{0}+\left(\alpha_{3}-\beta_{3}\right) \ln P^{\mathrm{avr}}+\left(\alpha_{4}-\beta_{4}\right) \ln P^{\mathrm{avr}-1}\right] \\
& \left.+[\ln A(1+g)]\left[1-k\left(\beta_{2}-\alpha_{2}\right)\right] /\left[\left(\beta_{1}+\beta_{2}\right)-\left(\alpha_{1}+\alpha_{2}\right)\right]\right] \\
& \times \frac{1}{k\left[\left(\beta_{1}+\beta_{2}\right)-\left(\alpha_{1}+\alpha_{2}\right)\right]}-\left[\frac{[\ln A(1+g)]}{\left[\left(\beta_{1}+\beta_{2}\right)-\left(\alpha_{1}+\alpha_{2}\right)\right]}\right] t .
\end{aligned}
$$

Hence,

$$
Q^{*}=e^{\left[k\left[\alpha_{0}+\left(\alpha_{3}-\beta_{3}\right) \ln P \operatorname{avr}+\left(\alpha_{4}-\beta_{4}\right) \ln P \operatorname{avr}-1\right]+[\ln A(1+g)]\left[1-k\left(\beta_{2}-\alpha_{2}\right)\right] /\left[\left(\beta_{1}+\beta_{2}\right)-\left(\alpha_{1}+\alpha_{2}\right)\right]\right] /}
$$

which is the intertemporal equilibrium value of quality.

A.2. Complementary function. To find this component of the solution, we need to consider the following reduced form of the second-order difference equation,

$$
\ln Q_{t+1}+\left(k \beta_{1}-k \alpha_{1}-1\right) \ln Q_{t}+\left(k \beta_{2}-k \alpha_{2}\right) \ln Q_{t-1}=0 .
$$

A possible general solution could take the form $\ln Q_{t}=A y^{t}$. Hence, $\ln Q_{t+1}=A y^{t+1}$ and $\ln Q_{t-1}=A y^{t-1}$. Substituting these expressions into the reduced form of the second-order equation, we get

$$
A y^{t+1}+\left(k \beta_{1}-k \alpha_{1}-1\right) A y^{t}+\left(k \beta_{2}-k \alpha_{2}\right) A y^{t-1}=0 .
$$

Canceling the common factor $A y^{t-1} \neq 0$,

$$
y^{2}+\left(k \beta_{1}-k \alpha_{1}-1\right) y+\left(k \beta_{2}-k \alpha_{2}\right)=0
$$

This quadratic equation could have at most two roots. Substituting $\alpha_{1}=0.902, \alpha_{2}=0$, $\beta_{1}=0.75, \beta_{2}=0.25$ into the quadratic equation and solving it for the roots, we get

$$
y_{1}=0.86, \quad y_{2}=0.29
$$

Thus, the solution for the reduced equation is

$$
A_{1} y_{1}^{t}+A_{2} y_{2}^{t}=A_{1}(0.86)^{t}+A_{2}(0.29)^{t} \text {, }
$$

where $A_{1}$ and $A_{2}$ are nonzero constants. 
A.3. The general solution. The general solution for the equation is the sum of the two solutions obtained in Sections A.1 and A.2,

$$
\begin{aligned}
\ln Q_{t}= & A_{1} y_{1}^{t}+A_{2} y_{2}^{t} \\
+ & {\left[k\left[\alpha_{0}+\left(\alpha_{3}-\beta_{3}\right) \ln P^{\mathrm{avr}}+\left(\alpha_{4}-\beta_{4}\right) \ln P^{\mathrm{avr}-1}\right]\right.} \\
& \left.+[\ln A(1+g)]\left[1-k\left(\beta_{2}-\alpha_{2}\right)\right] /\left[\left(\beta_{1}+\beta_{2}\right)-\left(\alpha_{1}+\alpha_{2}\right)\right]\right] \\
\times & \frac{1}{k\left[\left(\beta_{1}+\beta_{2}\right)-\left(\alpha_{1}+\alpha_{2}\right)\right]}-\left[\frac{[\ln A(1+g)]}{\left[\left(\beta_{1}+\beta_{2}\right)-\left(\alpha_{1}+\alpha_{2}\right)\right]}\right] t \\
= & A_{1}(0.86)^{t}+A_{2}(0.29)^{t} \\
+ & {\left[k\left[\alpha_{0}+\left(\alpha_{3}-\beta_{3}\right) \ln P^{\mathrm{avr}}+\left(\alpha_{4}-\beta_{4}\right) \ln P^{\mathrm{avr}-1}\right]\right.} \\
& \left.\quad+[\ln A(1+g)]\left[1-k\left(\beta_{2}-\alpha_{2}\right)\right] /\left[\left(\beta_{1}+\beta_{2}\right)-\left(\alpha_{1}+\alpha_{2}\right)\right]\right] \\
& \times \frac{1 \ln A(1+g)]}{k\left[\left(\beta_{1}+\beta_{2}\right)-\left(\alpha_{1}+\alpha_{2}\right)\right]}-\left[\frac{\left[\left(\beta_{1}+\beta_{2}\right)-\left(\alpha_{1}+\alpha_{2}\right)\right]}{\left[{ }_{2}\right)}\right] t .
\end{aligned}
$$

Hence,

$$
\begin{aligned}
Q_{t}=\exp \{ & A_{1}(0.86)^{t}+A_{2}(0.29)^{t} \\
+ & {\left[k\left[\alpha_{0}+\left(\alpha_{3}-\beta_{3}\right) \ln P^{\mathrm{avr}}+\left(\alpha_{4}-\beta_{4}\right) \ln P^{\mathrm{avr}-1}\right]\right.} \\
& \left.+[\ln A(1+g)]\left[1-k\left(\beta_{2}-\alpha_{2}\right)\right] /\left[\left(\beta_{1}+\beta_{2}\right)-\left(\alpha_{1}+\alpha_{2}\right)\right]\right] \\
& \left.\times \frac{1}{k\left[\left(\beta_{1}+\beta_{2}\right)-\left(\alpha_{1}+\alpha_{2}\right)\right]}-\left[\frac{[\ln A(1+g)]}{\left[\left(\beta_{1}+\beta_{2}\right)-\left(\alpha_{1}+\alpha_{2}\right)\right]}\right] t\right\} .
\end{aligned}
$$

Given the values of the parameters,

$$
Q_{t}=\exp \left\{A_{1}(0.86)^{t}+A_{2}(0.29)^{t}+1.186-0.101 t\right\} \text {. }
$$

The values of $A_{1}$ and $A_{2}$ could be obtained by specifying two initial conditions. However, for the purposes of our analysis, we do not need to know the values of those constants.

Since the absolute values of $y_{1}=0.86$ and $y_{2}=0.29$ are less than 1, as $t \rightarrow \infty, A_{1} y_{1}^{t}+$ $A_{2} y_{2}^{t}$ will converge toward zero, and hence the general solution converges toward the particular solution,

$$
Q^{*}=e^{1.186-0.101 t}
$$

which is nothing but the intertemporal equilibrium quality. Thus the system designed by the model has a dynamically stable intertemporal equilibrium. $Q^{*}$ indicates a diminishing quality over time (a moving equilibrium). As $t \rightarrow \infty$, the intertemporal equilibrium quality tends toward zero, leading to a low-quality trap. 
Table B.1. Performance $\left(P_{t}\right.$ : an average of the values of the performance factors below).

Tangibility.

(1) ... Hospital has up to date equipment \& technology.

(2) Physical facilities in ... Hospital are visually appealing.

$\begin{array}{lllllll}1 & 2 & 3 & 4 & 5 & 6 & 7\end{array}$

(3) Bathrooms are very clean in ... Hospital.

(4) Rooms of the ... Hospital are very clean.

(5) Meals are attractive in ... Hospital.

(6) Food has right temperature in ... Hospital.

(7) Nurses of the ... Hospital respect to privacy.

(8) Rooms are quiet in ... Hospital.

$\begin{array}{lllllll}1 & 2 & 3 & 4 & 5 & 6 & 7\end{array}$

(9) Parking is convenient in ... Hospital.

$\begin{array}{lllllll}1 & 2 & 3 & 4 & 5 & 6 & 7\end{array}$

$\begin{array}{lllllll}1 & 2 & 3 & 4 & 5 & 6 & 7\end{array}$

$\begin{array}{lllllll}1 & 2 & 3 & 4 & 5 & 6 & 7\end{array}$

$\begin{array}{lllllll}1 & 2 & 3 & 4 & 5 & 6 & 7\end{array}$

$\begin{array}{lllllll}1 & 2 & 3 & 4 & 5 & 6 & 7\end{array}$

$\begin{array}{lllllll}1 & 2 & 3 & 4 & 5 & 6 & 7\end{array}$

Reliability.

(10) Food are delivered by a certain time in ... Hospital.

(11) When staff of the ... Hospital promise $\begin{array}{lllllll}1 & 2 & 3 & 4 & 5 & 6 & 7\end{array}$ to do something by a certain time, they do it.

(12) They keep patients' records accurately in ... Hospital.

(13) Hospital charges are accurate in ... Hospital.

Responsiveness.

(14) They tell their customer exactly when services will be performed. $\begin{array}{llllllll}1 & 2 & 3 & 4 & 5 & 6 & 7\end{array}$

(15) Patients who will be discharge has prompt service from $\begin{array}{lllllll}1 & 2 & 3 & 4 & 5 & 6 & 7\end{array}$ employees of the ... Hospital for the discharging operations.

(16) Patients are delivered prompt services from nurses when the patient needs them.

(17) Patients who come to hospital get prompt service from employees of ... Hospital for the admission operation.

(18) Employees of ... Hospital are always willing to help their patients.

(19) Employees of ... Hospital explain customer's question appropriately about the discharging process.

(20) Employees of ... Hospital explain customer's $\begin{array}{lllllll}1 & 2 & 3 & 4 & 5 & 6 & 7\end{array}$ $\begin{array}{lllllll}1 & 2 & 3 & 4 & 5 & 6 & 7\end{array}$ $\begin{array}{lllllll}1 & 2 & 3 & 4 & 5 & 6 & 7\end{array}$ $\begin{array}{lllllll}1 & 2 & 3 & 4 & 5 & 6 & 7\end{array}$ question appropriately about any procedure.

(21) Treatment is explained to the patient very clearly in ... Hospital. $\begin{array}{llllllll}1 & 2 & 3 & 4 & 5 & 6 & 7\end{array}$

(22) Discharging process is explained to the patient's family.

$\begin{array}{lllllll}1 & 2 & 3 & 4 & 5 & 6 & 7\end{array}$

Assurance.

(23) Customers trust nurses of ... Hospital. $\begin{array}{lllllll}1 & 2 & 3 & 4 & 5 & 6 & 7\end{array}$

(24) Patients are sure that they recovered well before they discharged. $\begin{array}{lllllllll}1 & 2 & 3 & 4 & 5 & 6 & 7\end{array}$

(25) Patients trust billing in ... Hospital.

$\begin{array}{lllllll}1 & 2 & 3 & 4 & 5 & 6 & 7\end{array}$

(26) Patients can feel safe in their $\begin{array}{lllllll}1 & 2 & 3 & 4 & 5 & 6 & 7\end{array}$ transactions with ... Hospitals' employees.

(27) Patients can feel safe that nurses $\begin{array}{lllllll}1 & 2 & 3 & 4 & 5 & 6 & 7\end{array}$ of ... Hospital are knowledgeable.

\section{B. The questionnaire}

the questionnaire is shown in Table B.1. 
Table B.1. Continued.

Courtesy.

(28) Employees of ... Hospital is polite during admissions procedure. $\begin{array}{llllllll}1 & 2 & 3 & 4 & 5 & 6 & 7\end{array}$

(29) Employees of ... Hospital are polite during housekeeping process. $1120 \begin{array}{lllllll}1 & 2 & 3 & 4 & 5 & 6 & 7\end{array}$

(30) Nurses' behavior are very polite against customer. $\quad \begin{array}{lllllll}2 & 2 & 3 & 4 & 5 & 6 & 7\end{array}$

(31) Nurses are cheerful.

$\begin{array}{lllllll}1 & 2 & 3 & 4 & 5 & 6 & 7\end{array}$

(32) Visitors are treated well in ... Hospital.

$\begin{array}{lllllll}1 & 2 & 3 & 4 & 5 & 6 & 7\end{array}$

Empathy.

(33) Employees of ... Hospital know what the needs of their patients. $\begin{array}{llllllll}1 & 2 & 3 & 4 & 5 & 6 & 7\end{array}$

(34) Nurses of ... Hospital show personal attention to their patient. $\quad \begin{array}{lllllllll}1 & 2 & 3 & 4 & 5 & 6 & 7\end{array}$

Other measurements.

(1) $R_{t}^{p}$ : In the next year my use of... Hospital (the degree to $\quad \begin{array}{lllllll}1 & 2 & 3 & 4 & 5 & 6 & 7\end{array}$ which you would be willing to repurchase the service next year).

(2) $R_{t}^{s}$ : The degree to which the supplier would be willing to $\quad \begin{array}{lllllll}1 & 2 & 3 & 4 & 5 & 6 & 7\end{array}$ reprovide the service next year (question to the supplier).

(3) $S_{t}$ : My feelings towards ... Hospitals' services can be best described. $\begin{array}{llllllll}1 & 2 & 3 & 4 & 5 & 6 & 7\end{array}$

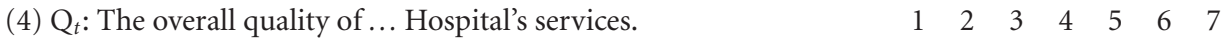

\section{References}

[1] S. S. Andaleeb, Service quality perceptions and patient satisfaction: a study of hospitals in the developing country, Social Science \& Medicine 52 (2001), no. 9, 1359-1370.

[2] A. C. Chiavg, Fundamental Methods of Mathematical Economics, McGraw-Hill, New York, 1988.

[3] A. Kara, A concept of optimal quality and an application, Total Quality Management and Business Excellence 16 (2005), no. 2, 243-255.

[4] _ Dynamic Modeling Exercises, Fatih University, Mimeo, 2000.

[5] A. Kara, M. Tarim, and S. Zaim, A Low performance-low quality trap in the nonprofit healthcare sector in Turkey and a solution, Total Quality Management and Business Excellence 14 (2003), no. 10, 1131-1141.

[6] L. X. Li and D. A. Collier, The role of technology and quality on hospital financial performance: an exploratory analysis, International Journal of Service Industry Management 11 (2000), no. 3, 202-224.

[7] P. C. Lim and N. K. H. Tang, A study of patients' expectations and satisfaction in Singapore hospitals, International Journal of Health Care Quality Assurance 13 (2000), no. 7, 290-299.

[8] (2000), no. 2, 103-111.

[9] S. A. Taylor and J. J. Cronin Jr., Modeling patient satisfaction and service quality, Journal of Health Care Marketing 14 (1994), no. 1, 34-45.

[10] U. Yavas and D. J. Shemwell, Modified importance-performance analysis: an application to hospitals, International Journal of Health Care Quality Assurance 14 (2001), no. 3, 104-110.

[11] F. N. Youssef, D. Nel, and T. Bovaird, Health care quality in NHS hospitals, International Journal of Health Care Quality Assurance 9 (1996), no. 1, 15-28.

Ahmet Kara: Department of Economics, Fatih University, Hadımköy, Büyükçekmece, Istanbul 34500, Turkey

E-mail address: econs@fatih.edu.tr 


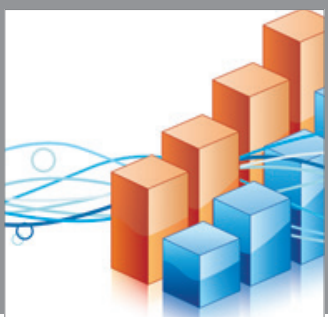

Advances in

Operations Research

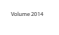

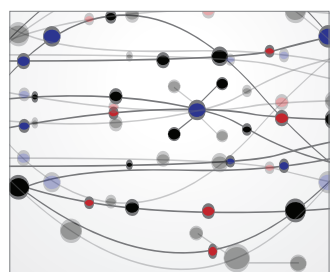

\section{The Scientific} World Journal
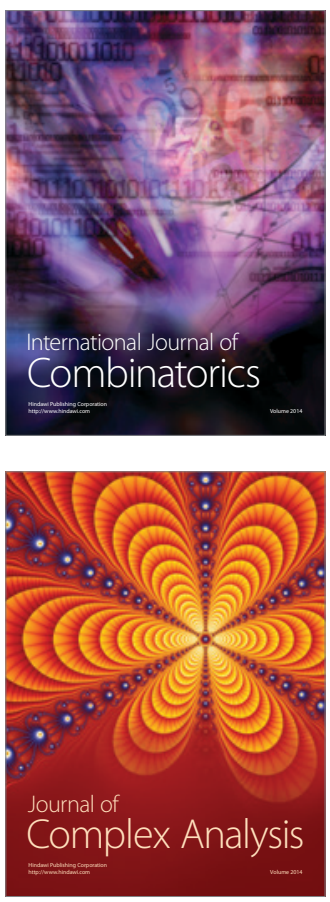

International Journal of

Mathematics and

Mathematical

Sciences
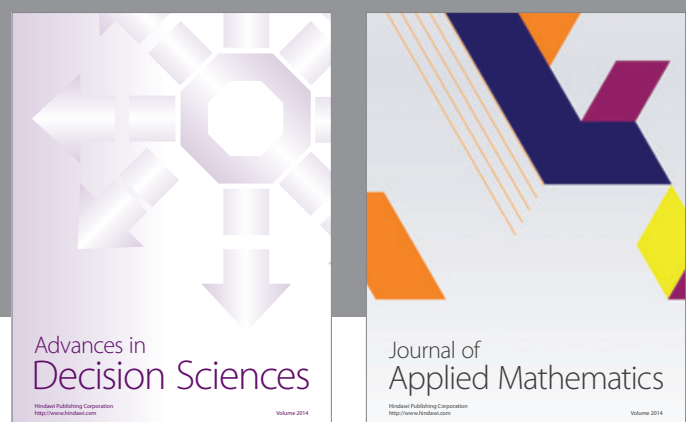

Journal of

Applied Mathematics
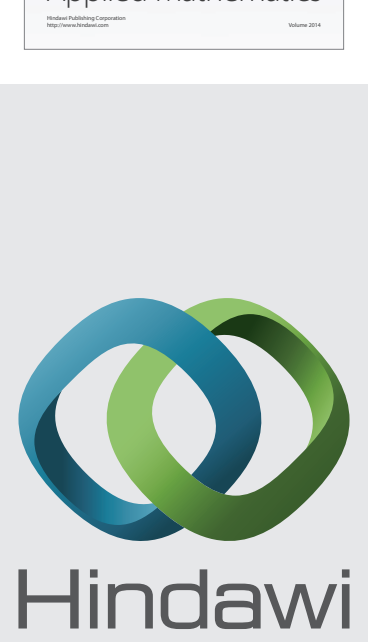

Submit your manuscripts at http://www.hindawi.com
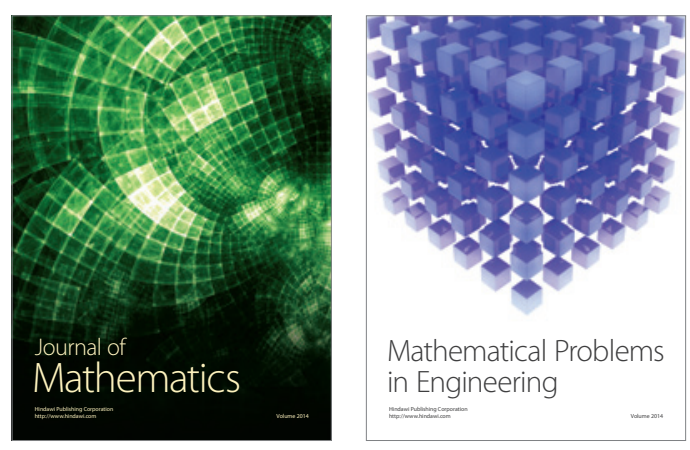

Mathematical Problems in Engineering
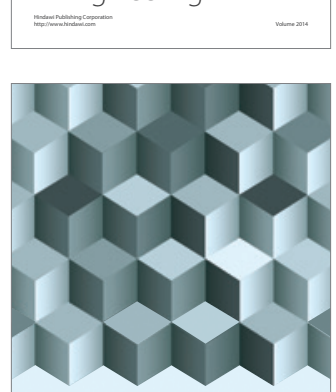

Journal of

Function Spaces
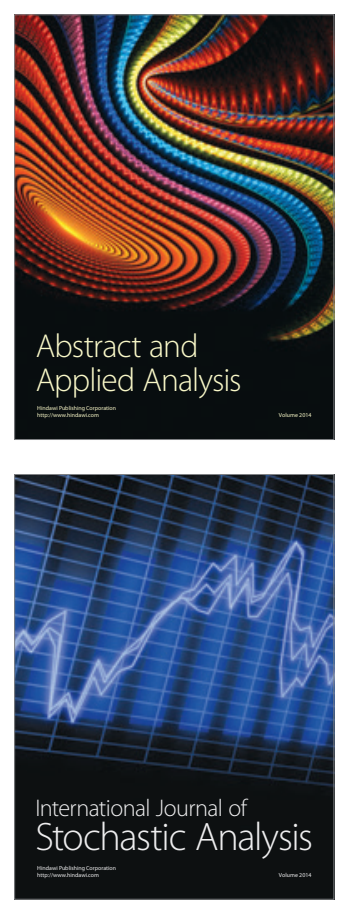

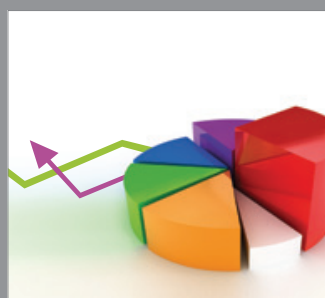

ournal of

Probability and Statistics

Promensencen
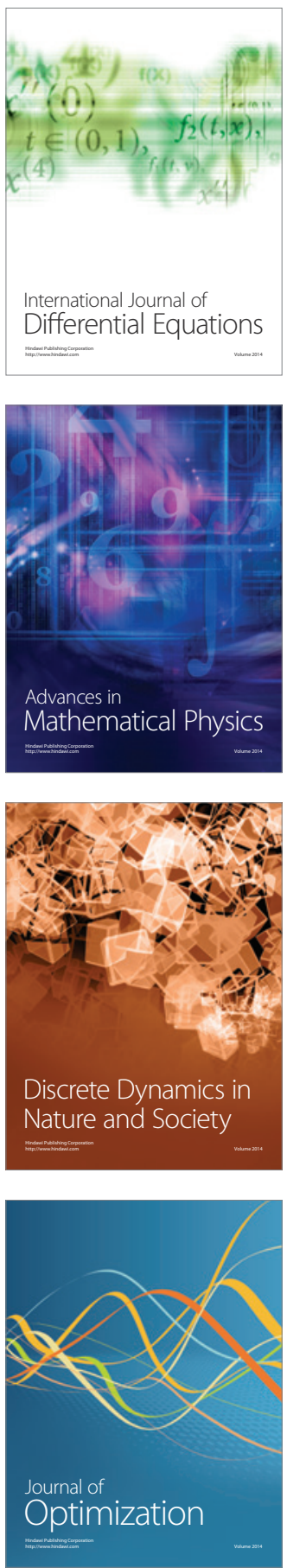